\title{
A model of ecowelfare
}

Post-productivism is therefore opposed to the social dominance of waged work, as this involves neglecting the reproductive value of emotional and ecological labour. As such, productivism has begun to reach the limits of itself because of its increasing inability to reproduce its own conditions. Like a dying star, productivism survives by consuming the waste that it has produced, it absorbs the consequences of too little care and too little sustainability by attempting to convert them into further sources of productivity. But these waste products are no substitutes for a proper ethics of care and sustainability, ethics that guide us beyond the employment society of endless GDP growth and endless productivity, so that this process cannot last indefinitely. Productivism does not necessarily reach a crisis - there is nothing historically inevitable about post-productivism - but it does implode into a cycle where productivist solutions are more and more ephemeral, re-inverting into further social problems at an everaccelerating rate. It is the disease that purports to be the cure.

So, over the last couple of chapters I have stressed the importance of care work and sustainability, on the basis that these continue to be underemphasised by social democrats, old as well as new. In addition to distributive justice, these are the philosophical foundations of an ecowelfare politics, of a post-productivist social democracy. We have already addressed the main features of distributive justice in Chapter 2 and so our task here, in the following two sections, is to give an account of care and sustainability. I will then provide a simple model of ecowelfare and explore the main points of creation and tension between its three principal components.

\section{Recognition and care}

For reasons that will become clear, I want to treat care not in isolation, but in relation to the principle of recognition (cf. Daly, 2002: 263). Recognition 
has become an important and controversial topic in recent years and may represent the single most important contribution that postmodernism, post-structuralism and the 'cultural turn' have made to radical politics. However, my argument will be that recognition is incomplete without reference to distributive justice and to an ethic of care. In turn, the deficits of this ethic can be repaired by relating it to that of recognition.

I first want to dispense with those who would either replace distributive justice with recognition or at least subvert the former to the latter. This is the position of Iris Young (1990) and Alex Honneth (2001) for instance. ${ }^{1}$ Young (1990: 15-16) wants to displace the distributive paradigm on the grounds that it is concerned with the distribution of material goods and social positions and so is too inert to be extended to social goods that are non-material and culturally dynamic. Honneth (2001: 53-4) insists that both recognition and distributive justice derive from the demand for social esteem so that, for instance, unemployment represents the denial of social esteem, because the unemployed person is left less able to engage in social cooperation than before.

The problem with Young's formulation is that although she is correct to cite potential problems with the distributive paradigm - the insensitivity of its abstract universalism to particularity - she then wants to shift paradigms altogether without considering the possibility of resiting distribution upon a more sophisticated universalism. So, although Young acknowledges the importance of distribution, by abandoning universalism altogether she leaves herself unable to reconcile distribution with difference and so continues to prefer the latter.

The problem with Honneth is that although unemployment may deprive an individual of self-esteem, this is a consequence of unemployment and not the motivating factor. Employers do not issue redundancies in order to reduce self-esteem, but as a response to market imperatives. Contrast that action with the racist joke. Of course, such instances may overlap, as when the employer makes only his black employees redundant, but although distributive injustice can take a cultural form, this does not mean that culture reaches 'all the way down' the system of production. Honneth might reply that such capitalist acts derive ultimately from the impulse to gain power over others by 'misrecognising' their moral worth, i.e. conflict within capitalism involves struggles for recognition rather than, as for Marx, the recognition of (economic) struggle (Honneth, 1995: 145-51). But by giving such weight to recognition, Honneth seems to propose that as recognition implies justice so injustice must imply misrecognition. Yet although this will often be the case (see below), this does not mean that injustice is no more than a form of misrecognition ( $A$ may imply $B$ but $B$ may imply both $A$ and not- $A$ ) and so Honneth neglects the possibility that we can have injustice even where we have recognition. 
This is precisely what is at stake in arguments about capitalism. Does recognition require (a) the equalisation of resource ownership, (b) equal opportunity for ownership or (c) an opportunity (however remote) for ownership? Because each may imply a recognition of equal worth, depending upon your social premises, adjudicating between them requires a theory of justice that cannot be reduced to 'moral feelings of indignation'.2

But if a politics of recognition is not enough, then should we be satisfied with a politics of distribution? Brian Barry (2001) has launched a wide-ranging attack on the political theorists who champion multiculturalism, minority rights, difference and recognition, accusing them of fashionable incoherence at worst or, at best, of saying nothing that cannot be accommodated within a philosophy of egalitarian liberalism. Barry's is an effective attack against those who would either abandon liberalism or else substantially reconstitute it around a differential politics of identity. At the extreme, this leads to a social morality of group separatism that was effectively satirised by Lukes (1995) and which Rorty (1998) and Klein (2000) condemn as having sent the American Left down the blind alley of political (or, more properly, 'cultural') correctness. The problem is that Barry tends to conflate these positions (anti-liberal multiculturalism and liberal multiculturalism) with a third that we can term 'multicultural liberalism'. His critique is therefore at its weakest when it is rejecting those who extol this third position.

For instance, Barry (2001: 138) presents Kymlicka as believing that 'selfgoverning national minorities should not be constrained by measures imposed by a liberal state to prevent violations of liberty and equality', in the course of outlining a liberal theory of group rights that substantially replicates that offered by Kymlicka (1995) himself. ${ }^{3}$ Similarly, Nancy Fraser is condemned for imagining that homosexuals need anything more than 'equal legal rights' (Barry, 2001: 274-9), a kind of don't-frighten-thehorses argument that neglects the varied reasons why the walls of gay and lesbian prejudice are gradually falling. I do not want to pick a fight with Barry, since he offers many ideas that are themselves consistent with a multicultural liberalism. Nevertheless, he often manages to simply invert the simplicities that he otherwise condemns in multiculturalism; as when, for example, he equates cultural identity with expensive tastes, or when he treats preferences as if they exist in a socio-cultural vacuum, or when universalism is presented as having to make no concessions to group differences (Barry, 2001: 34-5, 65, 114).

It is perhaps Fraser who therefore has come closest to outlining a liberalism that is both multicultural and distributive (1997, 2000; Fraser and Honneth, 2001; cf. Okin, 1989). Fraser (2001) notes how distributive justice and recognition are usually treated as incompatible, because the former 
is regarded as a question of 'the right' (Kant's notion of universal rules) and the latter as a question of 'the good' (the Sittlichkeit or ethical judgement that Hegel attributed to the embedded self). But Fraser's argument is that recognition, too, involves justice claims so that it can rescued from an identity politics which, in valorising group identity, everywhere risks a repressive and non-material communitarianism. Instead, recognition implies social status and participation on a par with others and is therefore opposed to the 'misrecognition' that is generated through institutional exclusion and forms of subordination. Challenging misrecognition therefore means ensuring a 'parity of participation' by distributing material resources in such a way that economic structures are just and through an equal respect being accorded to all social participants. Fraser observes that a certain pragmatism is required in judging who does and does not warrant recognition and whether recognition should imply universalistic or particularistic strategies. It is not the case that all groups deserve equal recognition. For instance, by denying participative parity to others, racist groups could be said to exclude themselves from equal social participation. Equal respect should therefore be accorded to all those who would not deny participative parity to others. In short, by elaborating upon a philosophy of right, Fraser offers a liberalism that is multicultural, without according equal value to all groups indiscriminately, and which can also encompass the economic, non-cultural dimensions of distributive justice. She steers a course between those who would either subvert distribution to recognition (Honneth), i.e. the economic into the cultural, or those who would collapse recognition into distribution (Barry), i.e. the cultural into the economic.

While agreeing substantially with Fraser, I would point to several potential weaknesses in her argument. First, to acknowledge that recognition involves justice claims does not commit us to the view that justice claims are all it involves. For instance, in a brief discussion of environmentalism, Fraser argues that the dispute between ecologists and anti-ecologists can be resolved with reference to the needs of future generations, needs of which only a Kantian, deontological approach can conceptualise. But, as I will argue in Chapter 7, although deontology is the most useful starting point for discussing future generations, any such discussion has to take account of the contingencies of the present and near future. Our conception of future generations will alter, depending upon whether ecological catastrophe is assessed as being 50 years away or 500 years. Therefore, although there are some future generations whose interests we should recognise, there are others (presumably in the more distant future) to whom we should be fairly indifferent. Yet this 'recognition' is such an integral part of the deontological equation that it cannot be determined by that equation itself. 
So the second potential weakness is that although Fraser makes room for pragmatic judgement, she perhaps underestimates the role that such judgement will have to play. Participative parity is an important benchmark but, unless we are to restrict our notions of 'participation' and 'parity' to some kind of all-purpose universalistic denominator, then contextual contingencies again become important. In the ecological example, there may be some future generations to whom we should be paternalistically accountable, but who cannot be said to enjoy parity with more immediate generations. Finally, Fraser (2001: 36-7) acknowledges that it may be necessary to turn to Sittlichkeit but, she insists, not until deontological reasoning has been exhausted. However, if the above criticisms are valid then the 'turn' cannot be delayed for very long, which is another way of saying that deontology cannot be exhausted without contextual judgement entering into it as an equative factor. Fraser's account of reasoning (deontology then Sittlichkeit) is too linear and dichotomous.

So although Fraser is correct to root both distribution and recognition in the 'right', we also have to make greater room than she allows for practical judgement (Bauman, 2001: Ch. 6). This practical judgement is what I here term 'care', defined as a means of negotiating between abstract justice claims and context-sensitivity. I am not going to spend much time defining care as this is covered thoroughly in the literature referenced below (also Kymlicka, 2002: 398-420) - see also the discussion of New Labour and care work in Chapter $2 .{ }^{4}$ In essence, though, care involves the following key features.

Care implies interdependency, i.e. an alternative to the independence/dependence distinction that infects social policy with all it implies for those not perceived as being willing to be productive by labouring for another in the formal economy. Interdependency implies a relational, dialogical concept of the self in contrast to the possessive self that pervades both economic and political markets. It refers to the solidaristic lifeworld which is our ultimate source of well-being. Care is therefore an expression of, and a means of, nurturing the webs that we weave around and through one another, often without knowing it; interdependency returning endlessly to itself in a loop we call society. Care is also an other-directed practice, in that both the giving and the receiving of care are gifts. Care cannot take place without action (whether in speech or gesture) directed towards others, yet because of the interdependency of which the self is made, 'gifting' should not be confused with 'giving'. Receiving is as much an act of gifting as is giving: to gift is to give by receiving and receive by giving. Love is the most perfect example of gifting in that the acceptance of another is a means of nourishing the other. ${ }^{5}$ Care is therefore not the same as charity. For whereas charity is unidirectional at best (or enlight- 
ened self-interest, at worst), gifting is multidirectional; charity fragments the self that gives from the self that receives, in line with Protestant individualism, where gifting unites the receiving and giving selves as an interdependent bond. Care is directed towards needs. While preferences are expressed as bargains and satisfied through exchange, i.e. a trade that satisfies both partners by confirming their separateness, needs are expressed as calls that can only be satisfied through interchange, the contraction of separation. Preference items are things to be ingested where need items are emotional harbours into which we can moor: the former takes in, the latter takes itself to. The calls of the needy are answered not to augment the needed, but so that it and the needy can mutually belong. That even our needs are so often institutionalised as demands, claims and entitlements is a sign of how far our moral cultures have lost themselves within productivist mazes. Finally, care implies attentiveness, meaning an empathy for multiple perspectives and sympathy towards interdependent others. It is an openness to all voices, especially those that normally go unheard, and a willingness to respond. The responsibilities of care are not primarily reciprocal, they are not triggered by an equivalent stimulus and do not take the form of exchange for visible, productive effort. First and foremost, responsibility involves listening for sounds of the invisible, the quiet screams of the vulnerable.

But if this is what care is then how is care to proceed? It is here that we part company with those who would have care proceed either religiously or conservatively through the world, as if care is too fragile to sustain categories and boundaries. The problem is that for every Simone Weil (1987) there are thousands for whom pain and suffering is to be welcomed either as a opportunity to share in divine grace or as an opportunity to demonstrate, through charity, the ultimate benevolence of capitalist inequality. Care must therefore proceed politically. Although the reservoirs of care may be infinite because, as imperfect social beings, we cannot draw from those wells quickly or simultaneously then caring is not a costless activity. Political conceptions of justice are therefore needed as guidance to how and why those costs should be borne.

We can first dispense with those who would exclude care from considerations of justice. Jaggar (1983), for instance, says that in order to adjudicate between different and competing interests we need a degree of objectivity and rationality that a care ethic, immersed as it is in the contingencies of particularity, cannot supply. In anything less than a world of harmonious interests a care ethic cannot suffice. But this runs up against an objection similar to that noted against Fraser, above: admitting that care cannot substitute for the justice perspective is not the same thing as excluding care from that perspective altogether. Imagining that the necessity of exclusion follows from the impossibility of substitution risks neglecting 
the perfectly legitimate features of adjudication that a purely rationalistic approach may overlook.

We should also dispense with those who would separate care and justice out into separate moral epistemologies and/or gendered ontologies (Elshtain, 1981; Gilligan, 1982). Here, the problem consists in recontextualising the elements that have been so sharply divided out. If care and justice co-exist in parallel epistemological worlds, then how are we to travel consistently and effectively between those worlds? One solution is to propose that the dividing lines are gendered: care is what women do best in the private sphere and justice is what men do best in the public. Feminist politics should then try to achieve parity between male breadwinners and female caregivers (Fraser, 1997: 55-9). But apart from the latent contradictions within this position - how can parity ever be achieved if our epistemologies are so gendered? - its coherence depends upon sacrificing considerable elements of social identity; to put it simply, women are called upon to suppress their need for public participation and men are called upon to suppress their need for caregiving and receiving. Such parity would be a perverse reflection of existing inequality.

The best recent work on care therefore attempts to bring care and justice more closely together. Take the following examples. Tronto (1993: 166-75) insists that care and justice should not be separated out into what she calls 'false dichotomies', as a justice perspective reveals the many problems that an exclusivist care ethic would involve. For Sevenhuijsen (1998: 59) care and justice are extensions of one another. Meyers (1998: 143) regards a care/justice distinction as antithetical to feminist politics and political theory. Noddings (2002: 22) insists that 'care supplies the basic good in which the sense of justice is grounded'.

Yet having reached this point the above authors are still neglecting an important aspect of care. Tronto (1993: 153) writes that, ' . . any attempt to posit a universal moral theory of care would be inadequate ... If all we can do is to determine universal principles about the need for care, then we will not be able to understand how well care is accomplished in the process of realising it.' Yet this stance is confusing. Tronto begins by stating that the attempt to posit a universal theory would be inadequate, but then immediately proceeds to acknowledge that although the attempt could succeed, the actual realisation of care is not the same as its theoretical formulation as a set of universal principles. But although it would be impossible to universalise each and every aspect of care, precisely because life is too messy and chaotic, to be both motivated and assessed, actions must be referred back to a universalist background in order to negotiate a way through the vagaries that are used to justify a care ethic in the first place. Should I first help the driver or the pedestrian when the latter has been more badly injured in an accident, but had stumbled out of a pub 
obviously drunk? Such dilemmas cannot be decided in some kind of court of moral universalism, but because when we act we act with principles, rather than leaving them behind, it is best to be clear about what a universalist reasoning reveals those principles to be.

Sevenhuijsen (1998: 64-8) goes even further than Tronto, adopting what looks like an anti-universalist position or rather a post-structuralism that treats universalism only ever as an ephemeral construction which is glimpsed occasionally through the storms of dialogical contestation (Butler et al., 2000). The problem here is that, in abandoning the 'liberal distributive paradigm', Sevenhuijsen leaves herself making a distinction between power and domination without any real explanation of where the distinction lies, without an account of why domination is nondistributive and without an exploration of anti-universalists' inability to either supplant or properly assimilate universalism (Fitzpatrick, 2002b). In order to avoid an overhasty marriage of care and justice, Sevenhuijsen risks an overhasty divorce that collapses back into the epistemological dichotomies that I criticised above.

Meyers (1998: 147) comes closer to explaining what a non-distributive form of domination means: it consists of some depriving others of the power that comes through interdependent relations. But, as above, what this depends upon is a separation of principles from practices and an insistence that morality involves sympathy for the disadvantaged (Meyers, 1998: 166-8). This is fine if we possess an acute moral sense of desert and disadvantage; the problem is when we remember that our moral sense is tutored in societies of conflicting needs, demands and interests for which an indiscriminate, all-embracing sympathy, cut adrift from principled frames of reference, is likely to be inadequate. Meyers attempts to address such objections by discussing the teaching of moral sympathy in schools, but does not explain why Professor Hume would be less biased in this respect than Professor Kant.

Finally, Noddings (2002: 24-31) regards caring for as the primary, natural state from which justice (caring about) derives and upon which it is dependent for its efficacy. She insists that to try and base justice upon rationalist foundations, as Rawls does, is to search for laws that do not exist. Natural care (affection, inclination) precedes justice claims, though natural care requires cultivation in families and schools, i.e. it is a virtuous disposition rather than a biological essentialism.

Noddings is correct to some extent, as the problem of defining justice and erecting just systems is only a problem for those who are virtuous enough to recognise the pull of justice in the first place. The problem arises when Noddings attempts to relegate rationalism to a subservient role. A social ethic of care, she says, revolves around the psychological instinct to 'stand with one's own', at which point a theory of justice is needed to 
ensure that this instinct does not work to the detriment of others. The trouble with this is that if moral boundaries are first drawn through psychological instinct, then any subsequent theory of justice is likely to reflect this bias and so may provide inadequate recognition of what is and is not harmful. Noddings allows for the possibility of justice tempering care (cultivation), but not of challenging it. Basing care upon 'neighbourly affectation' is to assume that the identification of one's neighbours is unproblematic, yet this assumption is dangerously myopic. Justice may sometimes need to work with the grain of psychological instinct and sometimes against it; justice may sometimes follow the lead of care but, when the care instinct proves to be parochial and prejudiced, it may also need to precede it. In short, what Noddings excludes is the possibility of an ethic of grounded universalism, an ethic of both justice and care that can identify moral laws based upon considerations of luck, disadvantage, responsibility and domination.

What the above theorists are doing then is either ignoring or downgrading a universalistic ethic of care, as if care is too fragile to cross the universalism-particularism borders. So whereas Fraser delays for too long the turn towards context, pragmatism and Sittlichkeit, for those such as Tronto the turn cannot come quickly enough. Therefore what is being missed here is an ethic of recognition and care that while grounded in a universal frame of reference is also sensitive to particularism. Not a universalism and then recognition/care - as Tronto (1993: 148) seems to imagine in her quip about universalists treating care as a 'moral fill-in' but recognition/care that is simultaneously universal and particular. Fraser (1997: 59-62) is hinting at this kind of move in her ongoing work on the 'universal caregiver model' and, while bearing the above criticisms of her in mind, it is this which may represent the best platform for future reflection.

For the sake of convenience, I propose to group recognition and care under the heading of 'attention'. Attention implies 'attending to', that is, we have a responsibility to recognise the diversity and difference out of which one's own identity is shaped; it also implies 'being attentive' or caring for the damage that is an ineluctable part of social and emotional relationships; finally, it also possesses a locutionary force (as in 'stand to attention!') that implies a systematic approach to justice and care, which avoids treating all groups or all care claims as being of equal moral worth.

\section{Sustainability ${ }^{6}$}

The key principle associated with environmentalism is that of sustainability though, like any key concept, this migrates around the political 
spectrum, reappearing in a number of ideological guises. This means that like its counterparts - 'equality', 'liberty', etc. - sustainability is overused to the point where it has become less rather than more precise. In its most famous definition, sustainability implies meeting '... the needs of the present without compromising the ability of future generations to meet theirs' (Brundtland Commission, 1987: 8), yet this apparently simple definition is contested and contestable. What do we mean by 'needs', 'the present', 'compromising', 'ability' and 'future generations'? The many possible answers to this and to numerous other questions are due to the sheer diversity of environmentalism.

Essentially, environmentalists identify a disjunction between what we demand of the world and what the world is capable of supplying. If the demands we make are infinite, yet the resources upon which we can realistically draw are finite, then ours is an unsustainable existence. Sustainability therefore refers to the process of reducing human demands and/or increasing resources, so that that disjunction is reduced.

Yet how can demands and resources be made to conjoin? This is where the controversies really begin to kick in (Dobson, 1998). One way is to expand the stock of resources, perhaps by replacing renewable resources, by substituting for non-renewable ones and by searching for technological solutions to the problems of depletion and pollution (Weizsacker et al., 1998). Let us call this approach one of 'weak sustainability'. A second way is to revise the demands that we make on the world so that, for instance, we consume far less than we do at present. So, rather than adapting the world to suit ourselves, we adapt ourselves to meet the finitude of nature. Let us call this approach one of 'strong sustainability'. A final way is to navigate somehow between those two approaches; call this 'moderate sustainability'.

Now I assume it is uncontroversial to state that since the Rio Conference of 1992, governments have preferred the 'weak' version of sustainability and have struggled to operationalise even this, the least ambitious of the three objectives just sketched. It would be surprising had weak sustainability not been the priority since sustainability is a collective action problem that both governments and electorates are notoriously slow both to recognise and to address. Policy-makers have thought it best to work from within the existing institutional forms of market and state and so the emphasis, to put it simplistically, has been upon changing the world, i.e. making resources go further, rather than changing society (Mol and Sonnenfeld, 2000). This form of 'ecological modernisation', an approach based upon the regulated market, has prevailed even in social democracies (see Chapter 5) with the insistence that the economy can be Greened without challenging its fundamental precepts. What is more surprising is the general lack of progress that has been made towards even weak sus- 
tainability. To some extent this has been due to the obstinacy of the USA yet, according to many Greens, it is also due to the inadequacies of ecological modernisation and the modesty of the weak sustainability at which it has aimed. The World Summit in Johannesburg in September 2002 is a useful illustration of this point. Corporations dominated the agenda, ensuring that voluntary guidelines rather than binding regulations would prevail. Poor countries were urged to make themselves more hospitable to inward investment, tying ecological policies into an agenda for privatisation and deregulation. Consequently, the summit concluded with only one major achievement (a sanitation target designed to halve the number of people without basic sanitation by 2015, the lack of which kills 1.3 million children a year) and a long list of failures.

If these criticisms are valid then what alternatives do Greens propose? As should be already clear, no simple answer to this question can be given since there are as many schools of Green thought as there are of socialist, libertarian, feminist thought, etc. Nevertheless, we might with only some distortion group those various schools under the headings already mentioned, the disagreement being fundamentally one of temporal scale and ecocentric range. For some, moderate sustainability should be the aim. This means working with a timeline of several centuries, where human and non-human interests are balanced in an ethic which is humanistic without being anthropocentric, and supporting a more radical adaptation of existing state and market practices. For others, this is still too modest an approach and we should be thinking across an even longer timeline that necessitates not piecemeal, techno-administrative reforms, but a rootand-branch restructuring of socioeconomic relations. Human interests are important (for all but a minority of anti-humanists), but only if those interests are recontextualised within a new biocentric ethic that does not centre around the human. This is the option of strong sustainability.

I am going to assume that moderate sustainability is the preferable path and a justification of this stance has been offered elsewhere (Fitzpatrick with Caldwell, 2001). For the time being, then, we assume that 'piecemeal, techno-administrative reforms' are appropriate even though this is regarded by the prevailing orthodoxy as too utopian and by the advocates of strong sustainability as not utopian enough. We do not have to spell out the full implications of moderate sustainability here, merely those that relate to social policy. So, what are the main critiques of state welfare made by the school of moderate sustainability and where might those critiques lead us?

\section{Critiques and proposals ${ }^{7}$}

First, environmentalists oppose social policies and welfare systems that are unsustainable and argue, as we have already seen in previous chap- 
ters, that indiscriminate economic growth is at the heart of all unsustainable practices. Despite this, economic growth is one of the logics of modern society whose value is usually unquestioned. It is the economic expression of the Enlightenment vision of historical progress and social development and, as such, almost all political philosophies have incorporated that productivist logic into themselves. Consequently, economic growth has become a form of meta-ideology, such that environmentalists often attract a kind of vitriol that productivist ideologies do not reserve for each other.

On these grounds, social policy leaves itself open to the criticism that existing welfare systems are dependent upon productivist practices that are ultimately unsustainable and that social policies contribute to unsustainability. The unifying factor here is the commitment to GDP growth that we have already explored. In essence, moderate sustainability therefore advocates a reconceptualisation of the economy and of economic activity that does not necessarily abandon the ethic of growth, etc., but certainly regards as inadequate the introduction of a few Green indicators into orthodox measurements and discourse.

This leads to the second Green critique of social policy, that it is too heavily based upon wage earning, whether as a source of material security, self-identity or social participation. Again, I do not want to revisit arguments already, made but there is one question that we have not addressed. Given the prevalence of productivist assumptions, is it not the case that environmentalists are arraying themselves against a series of opposing forces that they can never hope to defeat? Yet environmentalists are not quite as isolated as they first appear and it is precisely this post-productivist coalition that I am articulating in this chapter. Moderate sustainability does not argue for the abolition of employment, but for a recognition that security, identity and participation derive from a far wider range of sources and activities than the current orthodoxy admits. In this respect, ecologists side with those feminists who redefine flexibility towards employment, unpaid work and leisure away from restrictive masculinist conceptions of economic well-being. Indeed, since both ecologism and feminism argue for what I have here called 'reproductivity' (though the former stresses ecological labour and the latter emotional labour), then the scope for further convergence between these ideas is considerable. It is not the case that all forms of either feminism and environmentalism converge beneath the umbrella of post-productivist social democracy, since some will prefer productivist solutions and some will eschew social democracy altogether, but there are considerable numbers of those who challenge the employment-centred society (and includes many who might not identify themselves primarily with feminism or environmentalism, e.g. post-industrial socialists), so that the ecowelfare constituency may be very large indeed. 
The third main critique made by environmentalists towards social policy concerns the degree of control and autonomy currently possessed by individuals. The allegation is that existing forms of social organisation and welfare provision underestimate the extent to which citizens can be self-organising and most Greens are dissatisfied with the degree of centralisation that currently prevails. The state is interpreted largely as too distant and impersonal a set of institutions. Representative democracy is thought to encourage a passive, consumerist attitude towards the common good, one that minimises the level of political participation and organises participation around party machines that are top heavy (Doherty and de Geus, 1996). The assumption is that although most people care about the environment, this concern has barely registered on the mainstream political agenda since the party system embodies a status $q u o$ that is immensely slow to respond to new developments. And even where the Greens have had some success (Die Grunen, for instance), they have had to compromise to such an extent that their ideological distinctiveness is eclipsed.

In terms of social policy, this state centralisation is thought to encourage the 'clientalisation' of welfare, where well-being is something we receive from other sources (experts, bureaucrats) and rarely something that people collectively generate for and through themselves (Fitzpatrick, 1998b, 2002d). The price of paternalism and basic needs satisfaction has been an overarching collectivism that allows little space for bottom-up provision. Greens therefore tend to support not an ethos of Victorian self-help or the decentralisation of the market, but a new welfare settlement where the state provides a universalistic framework of regulation, accountability and basic service provision, but where greater room is made for civic associations (Hirst, 1994), decentralised policy communities (Ellison, 1999) or cooperation circles (Offe, 1996) that would control funds and allow the 'recipients' of welfare to become their own 'producers' (Barry and Proops, 2000: 93-4). We return to this debate in Chapter 9. In short, Green social policies seem to require a greater degree of 'decentralised collectivism' and the emergence of a new welfare citizen.

These Green critiques of social policy - focusing upon growth, employment and centralisation - are not exhaustive, but they do capture the main criticisms of social policy implied by moderate sustainability. As to where we go from here, well, the need is to design a doctrine that represents an alternative to ecological modernisation that is not only desirable but also viable. Again, I do not want to use space replicating arguments that have been made elsewhere (Fitzpatrick with Caldwell, 2001), but it is worth saying something here about what I call 'ecological radicalisation' (see Fitzpatrick, 2003c). 
If modernisation is essentially reformist, then radicalisation is more ambitious regarding both the means and ends of social transformation. This does not mean that radicalisation abandons reformism, but it does mean that reformism need not be limited to modest and relatively conservative objectives. Therefore, although radicalisation may overlap with the more ambitious aspects of ecological modernisation, it regards modernisation as the beginning rather than the end of social reorganisation (Christoff, 1996; van der Heijden, 1999). Consequently, rather than burying welfare reform within a broader concern for economic and public policies, social policy comes much more to the foreground. As noted in the introductory chapter, the job of this book does not involve offering a menu of policy reforms. Even so, given the fact that ecological radicalisation has to be both practical and ambitious, we perhaps need some idea of what it translates into. There are four key proposals worth mentioning in this context.

We have, first, already said something about BI in Chapter 2. A BI would be received by every man, women and child periodically (whether on a weekly, monthly or annual basis) as an unconditional right of citizenship, i.e. without reference to marital or employment status, employment history or intention to seek employment (van Parijs, 1992, 1995; Fitzpatrick, 1999a). What makes it appropriate for ecological radicalisation is the fact that BI represents the further evolution of the existing tax and benefit systems - and so of developments within that system towards tax credits - but also contains a potential for further social reorganisation, depending upon the form that a BI would take. In Chapter 7 I will suggest why a BI should be attached to the socialisation of substitutable resources and the reform of land taxation, an attachment that could satisfy both the Green and the socialist preference for the common ownership of, respectively, natural and social resources.

The second aspect of ecological radicalisation has already been touched upon in Chapter 5 and involves the demand that informal exchange and activity play a greater role in the ways in which we conceptualise and utilise reproductive value. One example of informal exchange that has attracted much attention in recent years is Local Exchange and Trading Systems (LETS). LETS are schemes to encourage people to exchange goods and services within their local communities (Williams, 2002). Each LETS is a non-profit-making network of local residents who trade goods and services with each other, using a local currency. The attraction of LETS for Greens is that local currencies encourage local trading and therefore place less pressure upon national and international infrastructures (J. Barry, 1999: 163-4). As with BI, then, the proposal that government facilitates much wider systems of informal exchange has one foot in present realities, since the informal 'economy' is considerably large 
already, and one foot in a future where work is no longer confused with employment.

This is also true of the third proposal consistent with ecological radicalisation: for systematic reductions in working time. The postindustrial Left are attracted to working-time reductions since, with more people in employment, the power of labour is enhanced (Gorz, 1989; Little, 1998). For Greens, the attraction lies in taking the emphasis away from paid work (although there is an additional requirement to ensure that the jobs which remain are made more ecologically friendly) and so in freeing up time for the wider range of activities which, as we noted in chapter 5 , they regard as important for social and environmental well-being.

The final recommendation is for a greater reliance upon ecotaxation (Robertson, 2002). Although the principle of ecotaxes is now widely accepted, so long as their economic and social benefits can be demonstrated, Greens tend to go further than the current orthodoxy allows. This may or may not involve support for much higher levels of ecotaxation than presently exist but, perhaps more importantly, it involves a radical change in the source of taxation. Land is of key importance here. In a globalised era, many worry that the levels of taxation needed to maintain high levels of social expenditure are not going to be sustainable. One possible solution is to shift the burden of taxation towards land, with those who occupy the most and/or the wealthiest land having the heaviest liability; and because land does not move - although its value certainly alters - then tax avoidance becomes less of a problem, though some form of global agreement and coordination is still required.

To conclude, moderate sustainability goes beyond the weak sustainability that governments, with varying degrees of enthusiasm and success, have been trying to implement in recent years, but it falls short of the strong sustainability that many within the Green movement argue for. My assumption is that moderate sustainability is the best we can aim for in the near future. This does not foreclose the possibility of moving towards strong sustainability in the longer term, but is to insist that it is more realistic to slow down the rate of unsustainability, rather than to attempt a premature leap into an ecological ideal that may divert us from more immediate and threatening problems. Moderate sustainability then criticises existing welfare systems in terms of their dependency upon growth, employment and centralisation and recommends what I have called 'ecological radicalisation'. Essentially, ecological radicalisation involves the refusal to treat 'reformism' and 'radicalism' as irreconcilable and involves the search for present-day trends that bear a post-productivist potential that may go unrecognised by the productivist orthodoxy. 


\section{The ecowelfare triangle}

We have now outlined the three components of ecosocial welfare and Figure 6.1 offers a simple model relating these together. I have made distributive justice, attention and sustainability the main nodes of this model, though a more elaborate one would give greater prominence to the various sub-nodes (equality of powers, etc.), multiplying the number of relations and directional flows accordingly. However, there is a reason, other than convenience, why I have plumped for simplicity.

One way to look at ecowelfare is from a considerable distance and do nothing more than recognise its main features: egalitarianism, multicultural liberalism, feminism and environmentalism. This bird's-eye view is helpful as a means of identifying the schools of thought that many have long considered necessary to the renewal of a radical politics, but it does skip over the details of debates with which I think we need to engage.

Figure 6.1 A model of ecosocial welfare

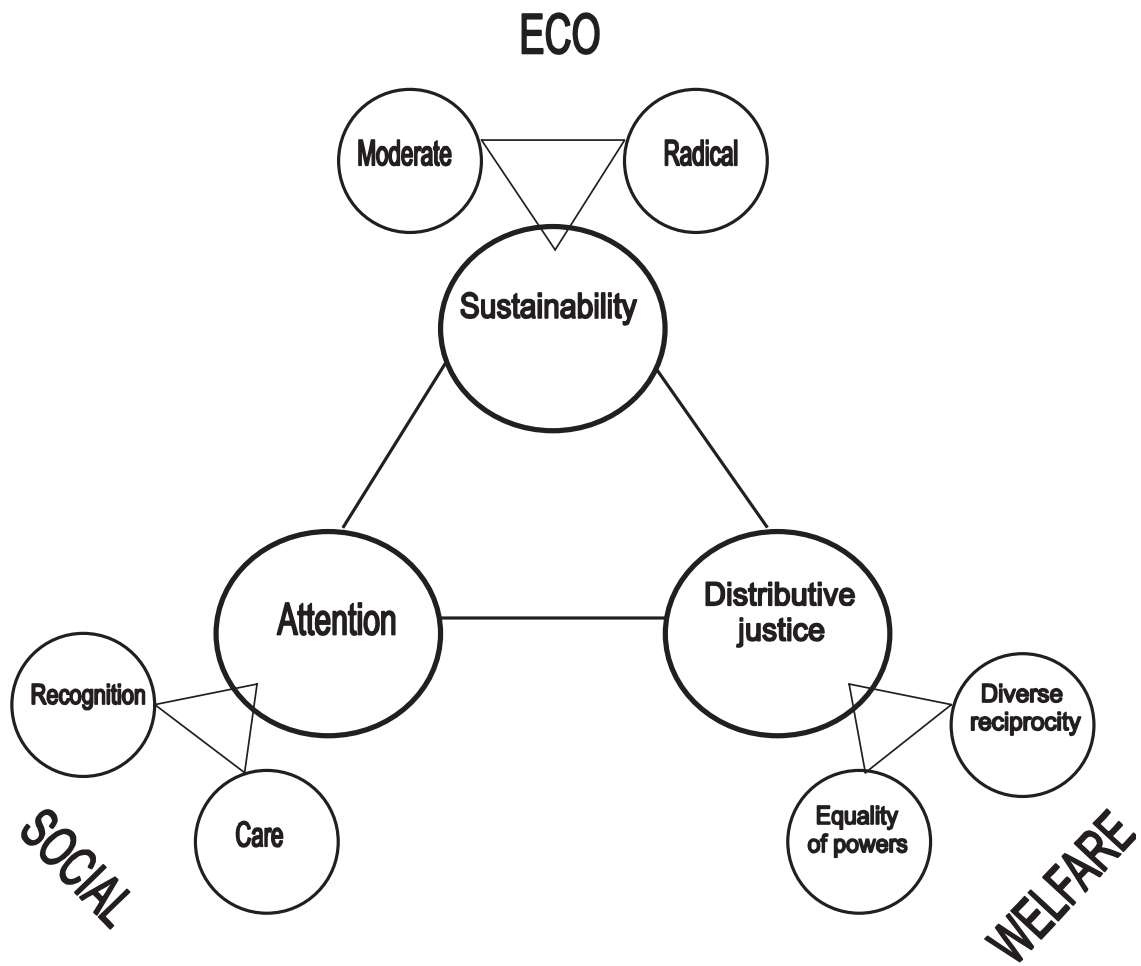


Alternatively, the arguments that have been presented in Chapters 2, 5 and 6 could be regarded as a take-it-or-leave-it proposal, as if disagreement with my account of recognition, or whatever, means that the whole structure is fatally flawed. This is to focus rather too much upon the details, though. Therefore, I want to offer a model that incorporates the specifics of my argument without alienating those who may disagree with certain of its features. Hopefully, Figure 6.1 does this, in that the relevance of the main nodes can be acknowledged even if some readers will prefer alternative accounts and descriptions of the sub-nodes. Obviously, those who stray too far from my position will either consider it to be too radical or else not radical enough (this being a common reaction to my conference papers!), but for others it will illustrate the broad church within which egalitarians, multiculturalists, liberals, feminists and environmentalists are congregating.

The analyses of the next three chapters therefore represent a means of applying this model to some of the key social questions we currently face, a way of working through where you and I may agree and disagree, rather than a comprehensive overview that could be interpreted as the last word, take it or leave it. Before we can proceed, though, I do need to flesh out the main connections of Figure 6.1 to set the scene for the following chapters.

\section{Sustainability and attention}

To what extent do the principles of sustainability and attention orbit around the same set of priorities and objectives? On one level the answer is simple. Unless we can guarantee levels of well-being similar to those we currently enjoy (and preferably higher) stretching into the foreseeable future, then recognition and care lose their force. This is not to claim that they become futile: just as there is value in caring for those who are terminally ill, so environmental catastrophe does not erase the force of moral obligations. However, such care work operates according to implicit assumptions of intergenerational continuity, where caring derives its value from the expectation that it stretches beyond the lifetimes of those who care and those who are cared for. But if the future is one of decline, then the moral injunction to attend to others is foreshortened and so less persuasive. This point is obviously simplistic as attention may well be a means of engendering the very sustainability upon which it depends for its moral suasion. As Chapter 5 sought to establish, care is a form of emotional labour that seeks to reproduce that which the productive economy cannot reproduce for itself and so may be thought of as a source of sustainability. Recognition, too, is a means of social preservation which is 
precisely why Barry (2001: 65) is opposed to the politics of recognition, arguing that either cultures will be preserved by those who identify with them or, if this is not the case, there is no point in maintaining them artificially - an argument that assumes what it seeks to prove, that cultures do not depend upon recognition.

In short, attention requires a timeline that reaches far beyond our lives and sustainability requires that we attend to each other more effectively than at present.

But this does not imply that these principles dovetail neatly. As the next chapter will make clear, there are temporal conflicts involved in any environmental ethic such that hard decisions have to be made about the allocation of resources. Recognition and care are not costless exercises, even if post-productivism revises our notions of what costs and benefits imply, and so there may be occasions when we need to sacrifice one principle in favour of another. I will spell out in Chapter 7 the rules that I think ought to govern us when such occasions arise and then in Chapter 8 we will address a specific aspect of the sustainability/attention debate. The point to be remembered here is that even were sustainability and attention to cohere 99 per cent of the time, there is still a residue that involves tradeoffs and the kind of context-sensitive judgements that we discussed earlier in this chapter.

\section{Sustainability and distributive justice}

The same is true when we relate these two principles together, only more so. In fact, Chapter 7 will concern itself primarily with the vexed question of relating sustainability (or intergenerational justice) to distributive (or intragenerational) justice. Although I do not want to anticipate the specific arguments that are pursued there, the general conclusion is similar to that above: sustainability and distributive justice are consistent with one another to some extent - and to a greater extent than is normally recognised, in fact - but although this minimises the trade-offs that need to be made; those are not eliminated entirely.

\section{Attention and distributive justice}

As already indicated above, Fraser $(1997,2000)$ has established the extent to which these principles overlap without either being reducible to the other (though she discusses recognition rather than care in this context). Misrecognition will accompany maldistribution more often than not, since denying needed resources to others is a means of lowering their selfesteem and so of raising your comparative status. Similarly, the unfair dis- 
tribution of resources is based upon the view that some possess less moral worth than others. ${ }^{8}$ Recognition therefore requires fair distribution as it is counter-productive, and possibly hypocritical, to valorise a cultural identity without ensuring that the members of that group have a fair access to the very resources without which the group may be unable to maintain its character. It makes no sense to celebrate ethnic difference while denying jobs and decent incomes to the members of ethnic groups. Conversely, distributive justice requires a fair distribution of cultural resources. The black household that is middle class and relatively affluent is materially better off than the black household which is on the breadline, but may still be subject to racism and discrimination. That the poorer household will be subject to the double burden of material and cultural deprivation does not mean that its oppression is only one of material injustice; cultural injustice also matters.

Nevertheless, these principles are not going to conjoin perfectly on each and every occasion. In a society of infinite resources and resourcefulness, we might be able to solve each and every aspect of misrecognition and maldistribution, but this is not our society. Therefore, there are times when we may have to prefer recognition to distribution. For instance, when the prosperous black household is being racially abused by its poorer, white neighbour, then justice might demand resources being allocated to the black household, as its need is more immediate. Poverty may be a source of the white household's hostility, but because racism is not only an economic category, then it cannot be resolved with purely economic measures, e.g. by giving more money to the white household. Equally, there are times when we may prefer distribution to recognition. For instance, where white children from poor backgrounds are performing less well at school than Asian children from more affluent ones, then more resources should be targeted at correcting for those socioeconomic circumstances than at issues of cultural recognition, even if there is an additional need for the latter.

Fraser's point, then, is that although recognition and distributive justice will overlap more often than not, such that addressing the one means addressing the other, this will not always be the case. Where I part company with Fraser is in believing that the turn to Sittlichkeit must be made earlier than she imagines (see above). But this turn does not leave us in a moral darkness, as there are still ways in which we can negotiate a way through the various dilemmas carefully and systematically: namely, by bringing the relevant groups together in a political community of discourse and dialogue. In Chapter 9, then, I will say something about deliberative democracy and why it offers a means of dealing with the kind of complex issues that cannot be automatically read off from political principles. 


\section{Conclusion}

Ecowelfare involves reference to the principles of distributive justice, attention and sustainability. In this chapter and in Chapter 2, I have outlined various theories which I think are needed to make sense of those principles, but hopefully without closing down any room for manoeuvre on the part of those who may disagree with various aspects of the relevant arguments. I have also suggested that while these principles push towards one another, there will be occasions where this is not so. But remember that there is nothing unusual about ecowelfare in this respect. Any liberally minded ideology is a broad church where, as in any church, members of the congregation often sing in different keys, a discordant harmony of those who nevertheless share similar visions and hopes.

\section{Notes}

1 Charles Taylor (1994) makes overtures in this direction but has not, to my knowledge, dealt with distributive justice at any length.

2 Honneth (1995: 165-6) does acknowledge that an ethic of recognition should not replace a theory of justice, but it is not yet clear how he is to reconcile the two without diluting his strong attachment to Hegelianism.

3 Which is not to claim that Kymlicka's account is unproblematic, merely that it is far more of a liberal account than Barry permits.

4 Note that although 'care' and 'caregiving' are obviously related the latter has been, and will continue to be, used in a more gender-specific sense than the former, i.e. to convey the (currently unfair) distribution of men and women across the public/private spheres.

5 Unfortunately, love also involves asking the loved one to share the damage that has been inflicted upon you by others and then unloving them when they do so. Love must damage itself to survive and just sometimes, by doing so, the self survives as well. We care for the damage we inflict on ourselves through others and so also for the damage we inflict on others by caring. If we did not care for each other, then we would have nothing and no-one to forgive.

6 For a longer account see Fitzpatrick and Cahill (2002a).

7 What follows will be fairly sketchy, as we have already anticipated many of these arguments in Chapter 5.

8 This is an argument similar to that made by Honneth (see above), but remember that our objection to Honneth was to his general neglect of the distributive paradigm. 